\title{
A recepção de Kant pelo jovem Schopenhauer em Sobre a quádrupla raiz do princípio de razão suficiente ${ }^{1}$
}

\author{
The Kant reception of the young Schopenhauer in On the Fourfold \\ Root of the Principle of Sufficient Reason
}

Die Kant-rezeption des Jungen Schopenhauer In Ueber die vierfache Wurzel des Satzes vom zureichenden Grunde

\section{Yasuo Kamata*}

Kwansei Gakuin University Quioto, Japão; Schopenhauer-Gesellschaft, Japan

1 KAMATA, Y. Die Kant-Rezeption des jungen Schopenhauer in Ueber die vierfache Wurzel des Satzes vom zureichenden Grunde. In: BIRNBACHER, D. (Hrsg.). Schopenhauers Wissenschaftstheorie: Der „Satz vom Grund“. Beiträge zur Philosophie Schopenhauers. Würzburg: Könishausen \& Neumann, 2015. Bd. 16. Tradução para a Língua Portuguesa de Eduardo Ribeiro da Fonseca e Julia Joergensen Schlemm. Agradecemos à Editora Könishausen \& Neumann (Würzburg, Alemanha) por gentilmente ceder os direitos desta tradução, destinada exclusivamente para publicação no Dossiê Schopenhauer Leitor de Kant.

*YK: Doutor, e-mail: emailbox@yasuo.kamata.de

Rev. Filos., Aurora, Curitiba, v. 30, n. 49, p. 236-254, jan./abr. 2018 


\section{Resumo}

O presente artigo parte das primeiras reflexões de Schopenhauer acerca da filosofia kantiana. Nesses textos de juventude, buscamos encontrar a formação dos pensamentos fundamentais da filosofia schopenhaueriana desde os seus primórdios em torno do problema da consciência, abrangendo o uso e as modificações de sentido da terminologia kantiana, as quais tinham a intenção de preservar o essencial da filosofia de Kant, mas, no mesmo sentido, purificando-a daquilo que o filósofo de Die Welt als Wille und Vorstellung supunha serem as suas dificuldades e contradições.

Palavras-chave: Consciência. Entendimento. Razão. Vontade. Representação.

\section{Abstract}

This article is based on Schopenhauer's first reflections on Kantian philosophy. In these youth texts, we seek to find the formation of the fundamental thoughts of Schopenhauerian philosophy from its beginnings on the problem of consciousness, encompassing the use and modifications of meaning of Kantian terminology, which were intended to preserve the essential of Kant's philosophy. But in the same sense, purifying it from what the philosopher of Die Welt als Wille und Vorstellung assumed to be its difficulties and contradictions.

Keywords: Consciousness. Understanding. Reason. Will. Representation.

\section{Zusammenfassung}

Dieser Aufsatz behandelt die kritische Kant-Rezeption des jungen Schopenhauer. In seiner Dissertation von 1813 kann man die Entstehung der Grundgedanken seiner Philosophie verfolgen, wie er nämlich die Kantische Terminologie im Wesentlichen übernahm und doch auf seine Weise modifizierte, was er für Schwächen und Widersprüche der Kantischen Philosophie hielt, bis endlich die Grundkonzeption der Welt als Wille und Vorstellung sich formte.

Stichwörter: Bewusstsein. Verstand. Vernunft. Wille. Vorstellung. 


\section{Introdução}

Nas próximas reflexões tentaremos acompanhar o desenvolvimento do pensamento fundamental da filosofia schopenhaueriana, principalmente, através da primeira edição publicada, em $1813^{2}$, de Sobre a quádrupla raiz do princípio da razão suficiente ${ }^{3}$. Ele cresceu na tradição filosófica kantiana e do idealismo alemão. Com isso, o debate de Schopenhauer com Kant não foi menos significativo do que o que ocorreu em relação a Reinhold, Schulze, Fichte e Schelling. Gottlob Ernst Schulze foi o primeiro professor de filosofia de Schopenhauer entre 1809 e 1811 em Göttingen. Através de sua crítica a Kant (SCHULZE, 1792) - mediada por Reinhold - , o jovem Schopenhauer prestou atenção, indiretamente, à importância da filosofia de Kant. A partir do semestre de inverno de 1811/1812, ele estudou em Berlim com seu segundo professor, Fichte, na expectativa de que este levasse adiante a filosofia kantiana. Sua insatisfação com os dois grandes filósofos contemporâneos se tornou o ponto de partida de sua própria filosofia, o que deve ter proporcionado os seus primeiros frutos em Sobre a quádrupla raiz. A preferência apaixonada de Schopenhauer por Schelling já no início de seu estudo abrangia, inicialmente, muito menos o momento de seu pensamento vinculado ao idealismo alemão subjetivista e muito mais o seu momento substancialista, sua romântica filosofia da natureza transmitida através desse pensamento ${ }^{4}$.

Os termos principais Wille e Vorstellung são dados aqui pela primeira vez no âmbito do que terá na sua futura obra magna $O$ mundo como Vontade e Representação (1818/1819) a sua delimitação conceitual fundamental. Nisso, a leitura intensiva e cuidadosa da Crítica da Razão

2 A maioria das edições de Schopenhauer disponíveis atualmente contém a segunda edição de Sobre a quádrupla raiz (1847). A primeira edição se encontra no volume 7 da Obra (Edição Hübscher, abreviada como Diss) e na versão digital do texto baseada na Edição Deussen Schopenhauer im Kontext III - CDROM/Download, Berlin, 2008, ISBN 978-39320-94-51-4, http://www.infosoftware.de/(01.06.2014). No presente documento, a primeira edição foi utilizada como fonte principal, tendo em vista a Naumburger Jubiläumstagung, para enfatizar as primeiras fases do problema filosófico da consciência em Schopenhauer. A segunda edição, lançada em meados do século dezenove e aumentada em cerca de setenta por cento, foi usada apenas de modo complementar.

3 Título daqui em diante resumido como Sobre a quádrupla raiz.

4 (р. KAMATA, 2006.

Rev. Filos., Aurora, Curitiba, v. 30, n. 49, p. 236-254, jan./abr. 2018 
Pura teve um papel decisivo ${ }^{5}$. Apesar de Schopenhauer pronunciar-se em crescente tom de crítica em relação a Kant, o fundamento de sua filosofia obtido em Sobre a quádrupla raiz permaneceu inalterado, como indica a exigência que ele faz aos leitores em sua obra principal: "que se leia a introdução [Sobre a quádrupla raiz] antes do livro" (W I, p. IX). Sua crítica se voltou contra os desvios inconsequentes que ele via em Kant, em relação ao que ele acreditava ser o fundamento da filosofia kantiana e que pensava ter corrigido em seus próprios escritos. Por isso, a veemência de sua crítica a Kant não deve ser tomada como uma crítica à filosofia kantiana como um todo ${ }^{6}$. Nossa tarefa será, considerando a terminologia kantiana, reconstruir, tanto quanto possível, a recepção de Schopenhauer à Crítica da Razão Pura na primeira edição de Sobre a quádrupla raiz (1813) (Seção 3 e 4). Com isso, esperamos encontrar um caminho que leve do pensamento definitivo da filosofia kantiana, como Schopenhauer entendia essa filosofia, ao pensamento definitivo da filosofia schopenhaueriana, como idealismo transcendental.

\section{O Problema Filosófico da Consciência no Jovem Schopenhauer}

No início de seu estudo universitário em Göttingen, a partir do sentimento de solidão e transitoriedade da existência e do pensamento a ela ligado de uma morte abissal7, Schopenhauer constata "o incerto, precário" [das Ungewisse, Mißliche] da vida (HN I, p. 10). Ansioso, ele se pergunta sobre a essência por trás do mundo fenomênico:

Na profundidade do humano existe a confiança de que algo fora dele seja tão consciente dele quanto ele mesmo. O oposto vividamente representado, ao lado da imensidão, é um pensamento pavoroso (HN I, 8, 2017, p. 219).

5 HN II, 268-287 e as notas correspondentes do Berliner Zeit em HN I, 20-34. Quanto à sua datação ver HN II, XI.

6 Ver, entre outros, Diss, 31 e W I, 491.

7 No tempo de estudo entre 1809 e 1813, estranhamente, não há relatos sobre a morte. Das notas posteriores a 1813, nas quais a expressão morte e morrer aparecem frequentemente, é evidente que o problema da morte pertencia, sem interrupção, às perguntas fundamentais do jovem Schopenhauer. Comparar, principalmente, HN I, $68 \S 99$, Hoyerswerda, 1813 e sua lembrança tardia na juventude: HN IV, 96 [36]. 
O sólido, no qual ele se apoia, e para ele o saber momentâneo, posto apenas em segundo plano, da verdade eterna, que é aquilo que o apoia a cada momento na vida (HN I, 10, 2017, p. 222)

Antes de muitos de seus contemporâneos, o jovem Schopenhauer viu no "Kant que tudo destrói" [alles zermalmenden Kant] ${ }^{9}$ o perigo de destruir também a esperança humana na existência de Deus e na salvação da solidão existencial. Schopenhauer diz: "O uso regulativo da razão em Kant é, talvez, o pior natimorto do entendimento humano" (HN I, 13, p. 224).

No entanto, com o aprofundamento do estudo de filosofia, a posição de Schopenhauer em relação a Kant mudou lentamente em favor do pensamento idealista, que havia recusado inicialmente. O conflito entre ser e não-ser, entre vida e morte, não pode ser superado, já que permanece no ambiente natural da dualidade exterior da consciência e do mundo externo. O filósofo deve proporcionar a superação desta dualidade através de um pensamento próprio: "A vida é uma coisa precária: eu me propus a fazer com que se reflita sobre isso" (Gespr, p. 22).

Deste modo, Schopenhauer deixou Göttingen em 1811 e mudou-se para Berlim. Lá, uma grande guinada se consumou em seu pensamento, muito na direção do idealismo kantiano e pós-kantiano. A sentença fundamental que representa a estrutura essencial de sua filosofia do mundo como representação ou fenômeno expõe que "ser significa apenas ser objeto para um sujeito ou sujeito para um objeto" (HN I, p. 26). Essa compreensão do ser se tornou o pensamento-guia em Sobre a quádrupla raiz:

Ser objeto para um sujeito e ser a nossa representação é a mesma coisa. Todas as nossas representações são objetos do sujeito, e todos os objetos do sujeito são nossas representações. Mas, nada que exista independente e por si mesmo, nada único e incoerente pode se tornar objeto para nós (Diss, p. 18).

8 Sempre que possível utilizaremos a tradução de Vilmar Debonna e Diana Chao Decock publicada na Revista Voluntas. (N. T.)

9 Esta expressão foi formulada e citada em vastos círculos pela primeira vez em Moses Mendelssohn, Horas Matutinas ou A Existência de Deus, Berlim, 1785, II. Schopenhauer também menciona a equivalente "Alleszermalmer", ou rolo compressor. Comparar com WI, 497.

Rev. Filos., Aurora, Curitiba, v. 30, n. 49, p. 236-254, jan./abr. 2018 
"Ser" é sinônimo de "ser objeto para um sujeito" e "ser representação". A substância existente em si que está fora ou ao fundo da consciência, logicamente, não tem espaço aqui. Logo após redigir a sua dissertação ele pronuncia palavras ainda mais claras: "Coisas em si, que existissem em si sem serem representadas, que, consequentemente, seriam outra coisa que não representações - representarmos coisas assim seria a maior contradição possível" (HN I, p. 96).

$\mathrm{O}$ anseio metafísico-religioso juvenil pela busca de algo sólido fora da consciência em si dos seres não é abandonado imediatamente, mas é gradualmente restringido e enfraquecido. $\mathrm{O}$ "sólido" nãoé mais procurado externamente, mas internamente à consciência humana, na qual apenas a distinção consciente e a mediação entre a finitude e a infinitude podem ocorrer. É uma posição sublime da consciência, que Schopenhauer denomina de "a consciência melhor" [das bessere Bewusstsein]. Quando essa expressão foi introduzida, ela ainda era acompanhada por um pouco de expectativa pela consciência transcendente que acompanhasse a razão às regiões inacessíveis do ser (comparar, por exemplo, com HN I, p. 23). Com o tempo, gradualmente, tal expectativa desapareceu. Deste modo, o que restou foi o pensamento acerca da duplicidade desta única Consciência, das duas posições da mesma, nomeadamente, aquela do mundo transitório, e essa aparente diferença que faz surgir surpreendentemente a "consciência empírica", que, por uma nova imposição de sentido, é revertida em "consciência melhor". Assim, a unidade do pensamento foi encontrada no âmbito da consciência, mas, ao mesmo tempo, a esperança de que o ser em si mesmo esteja ao fundo do mundo fenomênico se perdeu. Afinal, a consciência melhor só poderia significar a tarefa e a superação da própria consciência empírica, e a expressão "melhor" não tinha mais significado. Em 1814, ela foi, então, finalmente, abandonada como terminologia e no lugar entraram expressões como "a vontade se redireciona" [der Wille wendet sich] ${ }^{10} \mathrm{e}$ "supressão da Vontade" [Aufhebung des Willens] ${ }^{11}$. Ainda uma última vez, em 1814,

10 Ver HNI, $160(\S 263)$.

11 Comparar HN I, 189 (§ 306), 200 (§ 321), 227 (§ 365) e assim por diante. A famosa expressão "negação da Vontade" [Verneinung des Willens], no sentido da autonegação da Vontade [Selbstverneinung des Willens] só foi introduzida mais tarde - na verdade, quase que exclusivamente na obra principal. Os usos iniciais se relacionam à negação da Vontade 
aparece a expressão "Consciência melhor", mas já em uma configuração em grande medida metafísica:

A consciência melhor em mim já fica frequentemente assustada com a simples afirmação do meu corpo, e é por isso que o ascetismo, em que se pode até morrer de fome, grita de dor, quando eu, na afirmação do meu corpo, vou ao ponto da negação [Verneinung] do outro (HN I, p. 175).

No entanto, o pensamento de uma consciência melhor não morreu completamente. Ele permanece no entendimento de Schopenhauer acerca da filosofia. Paralelamente à dissolução do pensamento metafísico de diferença na duplicidade da consciência, existia uma diferenciação imanentemente consciente do pensamento. Isso significa: A pergunta filosófica primária do idealismo transcendental sobre a condição da possibilidade da experiência foi comparada à da consciência melhor e também denominada de "filosofia como arte", enquanto a explicação das coisas já consolidadas na realidade empírica foi assimilada à consciência empírica como fenômeno e denominada de "filosofia como ciência" 12, mais tarde depreciativamente batizada como "etiologia" ${ }^{13}$. A primeira é possível através do conhecimento de que "todas as coisas são apenas as nossas representações" (HN I, 135 f.). O consequente idealismo transcendental da imanência da consciência, tal como ele propõe em Sobre a quádrupla raiz, também pertence à categoria da consciência melhor: "O filósofo completo representa teoricamente a consciência melhor de forma pura, no que ele a separa precisamente e totalmente do empírico. $\mathrm{O}$ santo realiza o mesmo de forma prática" (HN I, p. 149).

A idealidade transcendental e a realidade empírica se complementam, mas na última forma de consideração da constituição das coisas dentro do mundo como representação em sua realidade empírica

desconhecida [die Verneinung des fremden Willens] (como injustiça [Unrecht]). Contrariamente, entre 1814 e 1816, expressões como "a Vontade se vira" [der Wille wendet sich] ou "virada da Vontade" [Wendung des Willens] foram utilizadas, a partir de 1815, frequentemente, também como "supressão da Vontade" [Aufhebung des Willens] e, depois de 1817, muitas vezes, como "abandonar a Vontade" [den Willen aufgeben] ou "0 abandono da Vontade" [Aufgeben des Willens]. Essa mudança terminológica extremamente interessante necessita uma pesquisa pormenorizada.

12 À filosofia como arte e filosofia como ciência ver HNI, 117 (§210); 128f. (§221); 139f. (\$239); 154 (§256); 186 (§301); 205 (§328).

13 Ver W I, 113-118 (§ 17) e, muitas vezes, no segundo livro inteiro e na "Conferência sobre a filosofia como um todo" (1820, Edição Deussen X). 
não podem responder sozinhas à pergunta filosófica primária sobre a condição da possibilidade do mundo como representação (comparar G, p. 28), mas recai no materialismo trivial. O jovem Schopenhauer também compartilhava desse ceticismo sobre a compreensão científico-materialista, sempre influente desde o Iluminismo. Na época do já então amplamente difundido materialismo, no meio do século 19, o velho Schopenhauer ainda se amparava com firmeza nos seus antigos pensamentos e via o perigo do materialismo até mesmo entre seus fiéis discípulos, como o seu "Erzevangelist [arquievangelista]" (GBr, p. 336), Julius Frauenstädt. Schopenhauer tentou se defender, nem sempre com sucesso, contra esta interpretação realista, ainda hoje aceita, da vontade como substância metafísica do mundo. Assim, em 1852, Schopenhauer escreveu as seguintes linhas a Frauenstädt, o qual acusou de ceder a uma tendência materialista e com o qual, provavelmente por causa disso, rompeu em 1856: "Na minha obra principal v. 2, p. 204, está, todavia, que 'A Vontade é a substância do Homem'; mas com isso também consta que isso é para ser compreendido 'em sentido figurado e metafórico'"' (GBr, p. 284) ${ }^{14}$.

Esta passagem ao mesmo tempo nos dá informação de que Schopenhauer designou a Vontade, por analogia, como substância ou também como coisa em si. Isso exige uma revisão em seus fundamentos da "analogia da vontade", uma vez que este é um conceito-chave da filosofia da natureza de Schopenhauer ${ }^{15}$.

Em conexão com a sua interpretação de Kant, Schopenhauer já havia exposto sua consequente noção fundamental da imanência da consciência em $O$ Mundo como Vontade e Representação, no apêndice à "Crítica à filosofia kantiana". Diferenciando da famosa crítica de Jacobi ao conceito de coisa em si (JACOBI, 1980, 302 f.), no sentido de seu segundo professor, Fichte, ele acusou Kant, por um lado, de "um preconceito antigo e enraizado", o qual é, em Kant, "o último fundamento

14 "Gleichnißweise" = Modo metafórico ou comparativo. Comparar também com GBr, 290 f. E últimas cartas de Schopenhauer, entre outras as de 30 de julho e 31 de outubro a Frauenstädt, GBr, 398 f. e 403f. assim como a última carta de 6 de dezembro de 1859, editada após longa interrupção, GBr, 464.

15 Ver a quarta seção deste artigo. 
da suposição de um objeto absoluto deste tipo, o qual em si, ou seja, mesmo sem sujeito, pudesse ser objeto" (W I, p. 524). Por outro lado, ele o acusa, no sentido de seu primeiro professor G. E. Schulze, de uma operação conceitual arbitrária, na medida em que esse objeto absoluto "através do conceito é adicionado ao intuído" [...] "Adicionar pelo pensamento esse objeto não diretamente representado pela intuição, é, então, a verdadeira função das categorias" (W I, p. 524).

Schopenhauer acreditava que a forma ideal da filosofia kantiana deveria continuar existindo, já purificada de tais dificuldades e contradições, e apesar de suas críticas múltiplas e ferozes a Kant em relação a aspectos particulares. Por isso, como vimos anteriormente, ele sustentava, inclusive na sua velhice, que a sua própria filosofia era o pensamento que dava acabamento à filosofia kantiana (P II, p. 142; W I, p. 595; W II, p. 10).

\section{A recepção a Schopenhauer à Analítica transcendental dos Conceitos e 0 desenvolvimento dos conceitos fundamentais de Vontade e Representação}

A partir da "dedução transcendental dos conceitos puros do entendimento" na Crítica da Razão Pura ${ }^{16}$, em particular seus pensamentos sobre a unidade sintética e unidade objetiva da apercepção, o jovem Schopenhauer obtém sua concepção fundamental para a representação da totalidade, que, posteriormente, será denominada "mundo como representação". A apercepção transcendental, apresentada na Crítica da Razão Pura como condição da possibilidade da identidade da autoconsciência e da unidade da representação, isto é, a autoconsciência, através de sua própria espontaneidade, originalmente concebe o seu objeto como tal em sua unidade sintética. O conhecimento empírico (a experiência) consiste na relação das múltiplas representações da intuição sensível ao conceito de um objeto com ajuda dos conceitos puros do entendimento

16 Immanuel Kant: Crítica da Razão Pura, 1781, citada depois da segunda edição de 1787 (abreviada como B), que o jovem Schopenhauer também leu. A primeira edição, que Schopenhauer posteriormente prezava mais, não era conhecida por ele neste momento. 
(categorias). Neste processo a priori de conhecimento, os objetos são mantidos unidos em uma autoconsciência como parte integrante desta experiência. Kant diz: "pelas simples razões de que eu posso compreender o diverso das mesmas em uma consciência, eu as denomino, em conjunto, de minhas representações" (B 134, p. 144b, itálico Y. K.).

Se deixarmos de lado, inicialmente, o entendimento diferente acerca da compreensão em Kant e Schopenhauer, esse princípio expressa o ponto de partida kantiano da perfeita imanência de consciência, que exclui do pensamento filosófico a consciência transcendente, o mundo externo em si mesmo, ou uma substância que ainda exista por de trás dele ${ }^{17}$. Schopenhauer comunica esses pensamentos no quarto capítulo, sobre a primeira classe de representações do princípio da razão suficiente do vir a ser: "Elas [as representações que constituem as experiências completas, Y. K.] constituírem a totalidade de uma experiência quer dizer: elas se encontram em uma relação reconhecível apenas pelo entendimento" (Diss, p. 21).

Com isso, continua-se com a pergunta sobre a relação entre a imediaticidade das intuições e a universalidade dos conceitos uns em relação aos outros. Schopenhauer a apresenta como a correlação entre os dois modos de representação, que são 1. A presença imediata de cada representação particular clara na autoconsciência, ou mais precisamente: na temporalidade do sentido interno; ela também é denominada de "ser representado $\kappa \alpha \tau^{\prime} \varepsilon v \tau \varepsilon \lambda \varepsilon \chi \varepsilon\left\llcorner\alpha \nu^{\prime}\right.$, e 2. A representação total, ou seja, as inatuais representações do todo da experiência como pano de fundo da clara representação imediatamente presente ("ser representado $\left.\kappa \alpha \tau \alpha \delta u v \alpha \mu \iota v^{\prime \prime}\right)$ na espaço-temporalidade ${ }^{18}$. Esta última, a inatual representação do todo, é, a saber, o que garante a unidade e estabilidade

17 Comparar "Seus princípios são meros princípios da exposição dos fenômenos, e o pomposo nome de uma ontologia, que se arroga a fornecer conhecimentos sintéticos a priori das coisas em geral em uma doutrina sistemática, pretende dar qualquer conhecimento sintético a priori sobre as coisas (o princípio de causalidade, por exemplo) em uma doutrina sistemática, tem de dar lugar ao mais modesto nome de uma mera analítica do entendimento puro" (B 303, 2016, p. 248).

18 Na terminologia da primeira edição da Crítica da Razão Pura, que Schopenhauer, em 1813, ainda não conhecia, ambos os polos da Synthesis, da verdadeira e espontânea ação da autoconsciência, a saber, a inicialmente instantânea Synthesis (apreensão) no sentido interno (ver A 99) e a representação de uma "unidade da Synthesis de todos os fenômenos a partir de conceitos" (A 108), conseguem trazer melhor à tona o que poderia ter sido também uma das razões concretas dos motivos pelos quais Schopenhauer prezava mais a primeira edição. 
do mundo (também), para o sentido externo, ou seja, a realidade empírica objetiva da totalidade da experiência, e o que chamamos na vida cotidiana de mundo objetivo real, apesar de que, na verdade, este não possa nunca ser negligenciado em sua totalidade, mas permanece apenas nossa representação da totalidade da experiência (comparar com Diss, 21, 23 f., G, 30). Como o sujeito do conhecer, que inicia espontaneamente o ato de conhecer e coordena tudo o que conhece (kantianamente: apercepção), não pode vir a ser conhecido como tal, assim o correlato desse conhecer, o todo da experiência ou a representação do total, como tal, não estão imediatamente presentes na consciência ${ }^{19}$. Na terminologia da obra magna, a representação do mundo objetivo real, ou seja, o mundo como representação, analogamente à concepção fundamental da Ideia platônica, precisou ser denominado de fantasma [Phantasma], reconhecido universalmente pela razão ${ }^{20}$, o que, intelectualmente, se aproxima, então, da "ideia do mundo" kantiana na dialética transcendental, no que ela permite um uso meramente regulativo, mas não constitutivo. Neste sentido, Schopenhauer explica na segunda edição de Sobre a quádrupla raiz, a realidade empírica como "uma representação total, a qual forma um [...] conjunto, mas com contornos problemáticos" $(\mathrm{G}, 30)$, que, então, não podem ser totalmente fundidos com os dados empíricos.

Essa compreensão do mundo como representação foi a resposta de Schopenhauer à pergunta de como, depois de Kant ter iniciado uma revolução contra o absolutismo (dogmatismo) filosófico, a unidade e a estabilidade poderiam ser garantidas no mundo. Essa libertação do pensar filosófico foi confrontada, ao mesmo tempo, com o perigo da liberdade absoluta da exigência de poder da razão, sobre o que G. E. Schulze já havia advertido em Aenesidemus ${ }^{21}$. Por isso, Schopenhauer,

19 Sobre incognoscibilidade do sujeito que conhece Kant e Schopenhauer concordavam: B 157 f., Diss, 72 f. (§43 f.).

20 A expressão de Schopenhauer quanto à Ideia Platônica, que é frequentemente mal interpretada, de forma parcial e emanationstheoretisch é, aqui, meramente indicada como é mostrado no ponto decisivo de 0 mundo como Vontade e Representação em que se expõe seu status transcendental-idealista: "A Ideia Platônica, a qual se torna possível pela união de fantasia [=faculdade imaginativa, comparar G, p. 27, Y. K.] e razão [Vernunft], constituirá 0 objeto principal [Hauptgegenstand] do terceiro livro deste escrito atual". W I, p. 48. Mais pormenores sobre o tema da Ideia platônica, ver KAMATA, 1989.

21 Ver SCHULZE, 1792, p. 402. 
no §24 de Sobre a quádrupla raiz (Diss, p. 31-44), volta-se contra a prova de Kant sobre a aprioridade do conceito de causalidade para mostrar que a unidade e a estabilidade da representação do todo não são, inicialmente, asseguradas pelo poder unificador da razão ${ }^{22}$, mas sim são dadas, de partida, pela estrutura da representação do todo até mesmo sem a intervenção [Eingriff] do conceito [Begriff].

O conceito da vontade, que foi abordado pela primeira vez no sétimo capítulo do Sobre a quádrupla raiz e que, com o tempo, toma uma posição cada vez mais importante na filosofia de Schopenhauer, remonta ao conceito kantiano de espontaneidade da autoconsciência, ou apercepção transcendental. Bem no início do sétimo capítulo se encontra: “O sujeito só é reconhecido como aquele que quer, uma espontaneidade, mas não como aquele que conhece" ${ }^{23}$. Aqui, a Vontade é abordada como espontaneidade, desde que ela cumpra a condição da possibilidade da experiência. Essa vontade eu gostaria de denominar de "Vontade transcendental" para distingui-la da Vontade que se objetiva no interior do mundo, com a qual nos deparamos dentro do já existente mundo como representação, ou seja, até o ponto em que a sua realidade empírica objetiva esteja assegurada e presumida ${ }^{24}$. Essa segunda vontade é designada, por exemplo, no segundo livro de O mundo como Vontade e Representação, onde é a "vontade na natureza" como a sua coisa em si ou, no quarto livro, que trata do seu "destino no mundo que reflete a sua essência" (W I, §60), onde é abordada como fonte do sofrimento. Este significado filosófico secundário da vontade

22 Aqui é preciso prestar atenção às diferentes definições de palavra, pois Kant descreve a razão [Verstand] como a capacidade [Vermögen] do conceito [Begriff], enquanto Schopenhauer chama essa capacidade de razão [Vernunft]. Todavia, para Schopenhauer, o entendimento também significa a capacidade da causalidade no sentido do Princípio da Razão Suficiente [Satzes vom zureichenden Grunde] do vir-a-ser [Werdens], mas essa causalidade não é um conceito a priori que mantém a unidade da totalidade da experiência [Erfahrungsganzen] do início ao fim, levando 0 entendimento a necessitar de um esquema, que para Schopenhauer é transcendental e duvidoso, mas que o princípio ordenador [Ordnungsprinzip] inerente à estrutura da representação é articulado, agrupado, de acordo com a representação total [Gesamtvorstellung]. Isso significa: o presente [Gegenwart] imediato da representação clara é mediado de um ponto de vista interno, de acordo com esta classe do Princípio da Razão Suficiente, pelo objeto imediato (corpo [Leib]) e em relação a outras representações, de um ponto de vista externo, pela representação total [Gesamtvorstellung]. Sobre esse ponto, ver Diss, p. 21-31.

23 Diss, p. 68. A equiparação de Vontade e espontaneidade também se encontra em HN I, p. 65; HN II, p. 349; 358.

24 Sobre a determinação conceitual da Vontade transcendental, ver KAMATA, 1988, principalmente 174 , entre outros. Nesse ponto da obra, a Vontade que se objetiva no interior do mundo, ou "A vontade na natureza", é denominada de "vontade dialética". 
na natureza foi mais influente na recepção de Schopenhauer do que o primeiro, especialmente quando Schopenhauer foi elogiado ou criticado como pioneiro do irracionalismo e do pessimismo.

Após consulta dos cadernos de estudos de Schopenhauer, conclui-se de que ele chegou ao pensamento da equiparação de espontaneidade e Vontade através da leitura de Ensaio de uma crítica de toda revelação (1792) e Sistema da doutrina moral (1798) de Fichte. Mas é claro que Schopenhauer se distancia do excesso especulativo de Fichte no que tange a essa comparação. Ao invés disso, ele remete a equiparação entre vontade e espontaneidade a Kant e tenta representar a Vontade no plano crítico transcendental meramente como a condição da possibilidade da experiência. A Vontade transcendental atua como espontaneidade cognitiva, que introduz a fantasia [Einbildungskraft] subjacente ao processo cognitivo humano. A Ideia platônica, que foi representada no sexto capítulo do Sobre a quádrupla raiz (comparar Diss, p. 63) como a intuição normal [Normalanschauung] apoiada na ideia normal [Normalidee] de Kant na Crítica do Juízo $0^{25}$, é designada, no plano transcendental-idealista, como "fantasma no presente da razão [Phantasma in Gegenwart der Vernunft]" (HN I, p. 130), ou seja, como produto da fantasia [Einbildungskraft]. Mais adiante consta: "Cada imagem é apresentada [darstellende] repentinamente à nossa fantasia, além disso, cada julgamento que não sucede ao seu fundamento anteriormente presente, precisa ser provocado por um ato de vontade" (Diss, p. 80). A fantasia é a "causalidade da vontade sobre o conhecer"26, pela qual a Vontade necessita do sujeito conhecedor para repetir, provocar ou chamar sua atenção para as representações que ainda não são percebidas. Essa é a determinação da vontade transcendental como espontaneidade, com a qual a filosofia primária tem que lidar como se fosse uma forma de arte.

25 Comparar HN II, p. 288. Embora esta passagem não dê nenhuma indicação concreta entre a relação ideal do conceito "intuição normal [Normalanschauung]"e"Ideia normal [Normalidee]", ela é evidente, por exemplo, em HN II, p. 362 (Caderno de estudos de Schopenhauer a Fries, Neue oder anthropologische Kritik der Vernunft, Heidelberg 1807, Heidelberg, 1807). Comparar também FRIES, 1807, v. 1, p. 237.

26 Diss, p. 80. A "causalidade" aqui citada não é idêntica à causalidade no sentido da primeira classe do princípio da razão suficiente do vir-a-ser; pelo contrário, ela compreende a espontaneidade da Vontade. Para evitar a confusão, na segunda edição, Schopenhauer corrigiu a expressão para "Influência da Vontade sobre o conhecimento" (G, p. 145). 
Por isso, a filosofia como uma arte pode nos dar explicação sobre o ser do mundo como Vontade e Representação. Apenas posteriormente, depois de 1815, com a introdução do pensamento da analogia da vontade como iremos esboçar rapidamente na próxima parte - , a determinação secundária do até aqui não refletido uso de "vontade na natureza" será alcançada à maneira filosófica.

Também na teoria schopenhaueriana da arte a vontade transcendental aparece como espontaneidade, que introduz a fantasia e, portanto, a atividade de síntese constitui um componente importante. Graças à capacidade produtiva da fantasia, o artista como gênio antecipa a Ideia platônica e a concretiza em obras de arte, mesmo que a natureza ainda não possa ou ainda não tenha conseguido produzir a beleza ideal ${ }^{27}$.

\section{A recepção de Schopenhauer à Analítica transcendental dos Princípios [Grundsätze] e a elaboração do conceito de experiência [Erfahrungsbegriff]}

Para o desenvolvimento do pensamento fundamental da filosofia de Schopenhauer, tanto o estudo da "Analítica transcendental dos conceitos" quanto a sua recepção da filosofia kantiana tirada de outros lugares da Crítica da Razão Pura, principalmente da "Analítica transcendental dos princípios", apresentam um papel importante. Sob uma visão sistemática, a doutrina das ideias, acima exposta como teoria da fantasia, deveria substituir o esquematismo transcendental para limitar, de acordo com Schopenhauer, o infundado domínio dos conceitos ${ }^{28}$. A recepção da analogia da experiência [Erfahrung], principalmente no ano 1815, na qual o conceito da analogia, totalmente em conformidade com Kant, entendido não como analogia matemático-constitutiva de proporção, mas sim meramente como analogia filosófico-regulativa (comparar B. 222), possibilita a transição teórica de seu conceito inicial de vontade

27 Ver W I, 262. Sobre a necessidade de se compreender essa antecipação do artista no contexto transcendental idealista, cf. Kamata, 1989.

28 Cp. KAMATA, 1988, 168 f. A equiparação de Schopenhauer, acima demonstrada, da intuição normal [Normalanschauung] e da ideia normal [Normalidee] no contexto do esquematismo kantiano demonstra essa intenção do jovem Schopenhauer. 
transcendental-idealista para o conceito de vontade na natureza, conseguindo com isso o fundamento da metafísica da natureza, que se tornou tão influente com o passar dos anos. Essa importante temática denominada de analogia da vontade, que vai muito além do momento de criação de Sobre a quádrupla raiz, está presente em outra pesquisa ${ }^{29}$.

Na dissertação de Schopenhauer existem muitos temas que indicam a sua profunda preocupação com a "Analítica dos Princípios". Eu vou me limitar aqui a dois exemplos importantes.

1. Um é a recepção de Schopenhauer aos "Axiomas da intuição" (comparar B 202) e às "Antecipações da percepção" (comparar B 206). Schopenhauer escreve, no §20 de sua dissertação, pouco antes de introduzir a estrutura da experiência, que consiste na presença imediata da clara representação ("ser representado $\kappa \alpha \tau$ ' $\varepsilon \nu \tau \varepsilon \lambda \varepsilon \chi \varepsilon\left\llcorner\alpha \nu^{\prime}\right.$ ") e da inatual representação completa: "então, ela [= a Consciência, Y. K.] pode ser apenas uma representação distinta, uma vez presente, ainda que esta possa ser multifacetada" (G, 23). Vamos prestar atenção aqui a duas expressões: "clara" [deutlich] e "complexa" [zusammengesetzt]. Percebe-se facilmente que a expressão "clareza" [Deutlichkeit], como o grau de percepção, que pode, então, desaparecer internamente até se tornar nada, refere-se à intensiva grandeza de representação, e que a expressão "complexa" se refere a uma sucessiva síntese de grandezas extensivas. Com a fantasia produtiva, Schopenhauer eleva essa síntese sucessiva ao extremo transcendental-filosófico permitido, a saber, à totalidade da experiência, de onde, mais tarde, surgirá a expressão o mundo como Representação. Pode parecer questionável se essa ampliação ocorreu inteiramente de acordo com o sentido da filosofia kantiana, na qual a ideia de mundo não é um fantasma [Phantasma], mas sim um conceito de totalidade. No entanto, do ponto de partida de Schopenhauer esta conexão é justificada pelo fato de a abstração dos conceitos serem oriundos da fantasia e pelo fato de representar um ato da Vontade. Essa é o fundamento filosófico primário transcendental-idealista para o aparecimento da Vontade como vontade

29 Ver KAMATA, 2014, p. 163-165. 
empírica na natureza, como, por exemplo, no intelecto como $\mu \varepsilon \chi \alpha \nu \eta$ [máquina] da Vontade (W I, 179).

Em relação ao problema da consciência que o jovem Schopenhauer abordou a partir do estudo com seus dois professores, G. E. Schulze e Fichte, a estrutura da experiência, que de acordo com a correlação do presente imediato consiste da clara representação e da inatual representação total, era uma imanente interpretação da experiência sem ambição de dominação dogmático-metafísico-substancial e arbitrário-subjetivista, aceitável e adequada à consciência transcendental-filosófica das pessoas do novo tempo.

2. O outro exemplo é a recepção de Schopenhauer da primeira analogia da experiência sobre a substância/matéria como perceptibilidade no tempo e no espaço. A compreensão de Schopenhauer sobre matéria corresponde à de substância na analogia kantiana da experiência, o que Frauenstädt, tão merecidamente responsável pela difusão da filosofia schopenhaueriana, e muitos outros discípulos de Schopenhauer, infelizmente, nunca viram desta forma ${ }^{30}$. O próprio Kant na "Analogia da experiência" esclarece o conceito transcendental-filosófico da substância do seguinte modo:

O tempo não pode ser percebido em si mesmo. Consequentemente, tem de ser encontrado nos objetos de percepção, ou seja, nos fenômenos, o substrato que representa o tempo em geral, e no qual toda mudança ou simultaneidade possa ser percebida na apreensão por meio da relação dos fenômenos a ele (B 225, 2016, p. 202).

Bem de acordo com essa acepção kantiana, em sua dissertação, no §19, o jovem Schopenhauer introduz o conceito de matéria primeiramente como perceptividade no tempo e no espaço (ver Diss, 21). Essa definição será repetida posteriormente no $§ 42$ assim como muitas vezes no primeiro livro de $O$ mundo como Vontade e Representação. A equivalência dos conceitos de matéria e substância no contexto transcendental-idealista será congelada na segunda edição de Sobre a quádrupla raiz: "a substância (ou seja, a matéria) persiste" $(G, 30)$.

30 Ver a segunda seção do artigo aqui exposto. 
Portanto, nesse ponto também aparece a continuação filosófica de Kant em Schopenhauer, comprovada pela sua recepção da Analítica dos Princípios. Deste modo, o conceito de substância não é para ser entendido como algo que existe em si além ou ao fundo do mundo fenomênico, mas é ele mesmo uma representação, que, na ordem das coisas, como fenômeno ou no mundo como representação forma um nó persistente e assim assume o papel de uma (quase) substância ou matéria. De acordo com essa compreensão de substância surgirá posteriormente a Analogia da Vontade.

\section{Panorama: a recepção kantiana depois de Sobre a quádrupla raiz (1813) até a criação da obra principal 0 mundo como Vontade e Representação (1818/1819)}

O desenvolvimento filosofia schopenhaueriana ainda não estava concluído com a Sobre a quádrupla raiz. As mais importantes etapas filosóficas até a elaboração da obra principal, na qual os círculos temáticos sobre o corpo, a natureza, a Ideia platônica, a arte, o ensino social, a ética e a negação da Vontade são trabalhados, são frequentemente ainda mais compreensíveis sob a luz da recepção kantiana. Esse reconhecimento evidentemente não exclui outras tentativas de reconstrução da filosofia inicial de Schopenhauer, na qual conflitos deste com outros filósofos como Fichte e Schelling ou com outras linhas de pensamento como a velha filosofia indiana e a filosofia budista são profundamente trabalhados. Para possibilitar a divulgação da importância do significado filosófico, histórico e contemporâneo da filosofia schopenhaueriana, que surgiu em um ambiente não apenas filosófico, mas também histórico-cultural e sociopolítico complexo, as tentativas de tirar conclusões sobre o pensamento filosófico de Schopenhauer em diversos contextos problemáticos podem prestar uma grande contribuição à pesquisa futura. 


\section{Referências}

FRIES, J. F. Neue oder anthropologische Kritik der Vernunft. 3 Bde. Heidelberg: Mohr \& Zimmer, 1807.

JACOBI, F. H. David Hume über den Glauben, oder Idealismus und Realismus. Ein Gespräch (1787). In: Jacobi’s Werke. Bd. 2 (1815). Nachdruck Darmstadt, 1980. p. 1-310.

KAMATA, Y. Der junge Schopenhauer. Genese des Grundgedankens der Welt als Wille und Vorstellung. Freiburg/München, 1988.

KAMATA, Y. Die Platonische Idee und die anschauliche Welt. SchopenhauerJahrbuch 70. 1989. p. 84-93.

KAMATA, Y. Der Einfluss von G. E. Schulze und Schelling auf Schopenhauers Theorie der Willensverneinung. ZurStandortbestimmung der Schopenhauerschen Philosophie. In: HÜHN, L.; SCHWAB, P. (Hrsg.). Die Ethik Arthur Schopenhauers im Ausgang vom Deutschen Idealismus (Fichte/Schelling). Würzburg, 2006. p. 203-212.

KAMATA, Y. Der Handschriftliche Nachlass und der junge Schopenhauer. In: SCHUBBE, D.; KOßLER, M. (Hrsg.). Schopenhauer-Handbuch. Stuttgart/Weimar i.E. Stuttgart/Weimar, 2014. p. 156-166.

KANT, I. Crítica da Razão Pura. Petrópolis: Vozes, 2016.

SCHOPENHAUER, A. Sämmtliche Werke. Ed. Julius Frauenstädt. Leipzig: Brockhaus, 1877. $6 \mathrm{v}$.

SCHOPENHAUER, A. Schopenhauer im Kontext III. Berlin, 2008. CD-Rom/ Download. ISBN 978-39-32094-51-4. Disponível em: <http://www.infosoftware.de/>. Acesso em: 1 jun. 2014.

SCHOPENHAUER, A. Arthur Schopenhauers Sämtliche Werke in 12 Bänden. Mit einer Einleitung von Dr. Rudolf Steiner. Stuttgart: Cotta, 1894-1896.

SCHOPENHAUER, A. Sämtliche Werke. Edição e comentários críticos por Wolfgang Frhr. von Löhneysen. Stuttgart; Frankfurt am Main: Cotta-Insel, 1960-1965. $5 \mathrm{v}$. 
SCHOPENHAUER, A. Manuscritos juvenis. Trad. Vilmar Debona e Diana Chao Decock. Revista Voluntas: Estudos sobre Schopenhauer, v. 8, n. 1, p. 215225, 1 sem. 2017.

SCHULZE, G. E. [anônimo]. Aenesidemus oder über die Fundamente der von dem Herrn Prof. Reinhold in Jena gelieferten Elementar-Philosophie. Nebst einer Vertheidigung des Skeptizismus gegen die Anmaaßungen der Vernunftkritik. 1792.

Recebido: 08/02/2018

Received: 02/08/2018

Aprovado: 22/02/2018

Approved: 02/22/2018 